\title{
Quantifying crop pollinator-dependence and pollination deficits: the effects of experimental scale on yield and quality assessments
}

Article

Accepted Version

Creative Commons: Attribution-Noncommercial-No Derivative Works 4.0

Webber, S., Garratt, M., Lukac, M., Bailey, A., Huxley, T. and Potts, S. (2020) Quantifying crop pollinator-dependence and pollination deficits: the effects of experimental scale on yield and quality assessments. Agriculture, Ecosystems and Environment, 304 (1). ISSN 0167-8809 doi: https://doi.org/10.1016/j.agee.2020.107106 Available at https://centaur.reading.ac.uk/91967/

It is advisable to refer to the publisher's version if you intend to cite from the work. See Guidance on citing.

To link to this article DOI: http://dx.doi.org/10.1016/j.agee.2020.107106

Publisher: Elsevier

All outputs in CentAUR are protected by Intellectual Property Rights law, including copyright law. Copyright and IPR is retained by the creators or other copyright holders. Terms and conditions for use of this material are defined in the End User Agreement. 


\section{www.reading.ac.uk/centaur}

\section{CentAUR}

Central Archive at the University of Reading

Reading's research outputs online 
1 Quantifying crop pollinator-dependence and pollination deficits: the effects of experimental scale

2 on yield and quality assessments

3

4 Sean M. Webber

5 (Corresponding author)

6 Centre for Agri-Environmental Research, School of Agriculture, Policy and Development, University

7 of Reading, Reading, Berkshire RG6 6AR, UK

8 seanwebber@hotmail.co.uk

9

Michael P. D. Garratt

11 Centre for Agri-Environmental Research, School of Agriculture, Policy and Development, University of Reading, Reading, Berkshire RG6 6AR, UK m.p.garratt@reading.ac.uk

Martin Lukac

Centre for Agri-Environmental Research, School of Agriculture, Policy and Development, University of Reading, Reading, Berkshire RG6 6AR, UK

m.lukac@reading.ac.uk and

Faculty of Forestry and Wood Sciences, Czech University of Life Sciences Prague, Prague, Czech Republic.

Alison P. Bailey of Reading, Reading, Berkshire RG6 6AR, UK a.p.bailey@reading.ac.uk 
Faculty of Agribusiness and Commerce, Lincoln University, Lincoln 7647, Canterbury, New Zealand alison.bailey@lincoln.ac.nz

30

Theresa Huxley

theresa.huxley@sainsburys.co.uk

Simon G. Potts

Centre for Agri-Environmental Research, School of Agriculture, Policy and Development, University of Reading, Reading, Berkshire RG6 6AR, UK s.g.potts@reading.ac.uk

\section{Abstract}

Many crops are known to be dependent on biotic pollination, but knowledge gaps remain regarding the extent of this dependence, how it varies between crop varieties, and the implications of biotic pollination for crop quality. Data is also lacking on the prevalence and extent of pollination deficits and the ability of the surrounding pollinator community to provide pollination services. Robust and standardised methodologies are crucial for pollination studies. However, there has been only limited research into the critical question of the appropriate scale to apply these methods. Here, we use a commercially important UK apple Malus domestica variety (Gala) to address the questions of pollinator-dependence and pollination deficits, quality benefits arising from pollination, and the implications of conducting pollination experiments at three different scales: the inflorescence, the branch, and the whole plant. 
We found that Gala apple production was highly dependent on biotic pollination: overall, pollinator exclusion reduced fruit set at harvest to $55 \%$ of open pollination levels, whilst supplementary pollination led to fruit set of $167 \%$. However, significant differences were found between the inflorescence, branch, and tree experiments; with increasing scale of observation leading to a lower measure of pollinator-dependence and pollination deficit. At the inflorescence scale, fruit set at harvest was just $13 \%$ of normal levels following pollinator exclusion, whilst at the branch and tree scales it was $75 \%$ and $79 \%$ of normal levels respectively. Supplementary pollination led to fruit set of $218 \%, 172 \%$, and $117 \%$ of normal rates at the inflorescence, branch, and tree scales respectively. Apple seed set was also significantly affected by pollination treatment and the extent of this effect also depended on experimental scale. These differences due to experimental scale are likely a combination of methodological, biological and crop management factors. Seed numbers were shown to be a very good indicator of a number of fruit quality parameters, with greater seed numbers resulting in greater production of Class 1 (i.e. top commercial value) fruit.

It is recommended that to measure pollinator-dependence and pollination deficits, experiments are conducted at the largest scale practicable and that treatment effects are monitored until harvest to more accurately reflect final yield outcomes. For apples, growers are recommended to record seed number as part of their fruit quality monitoring programmes to give a rapid and easy to measure indication of potential pollination deficit.

\section{Keywords}

Apple pollination, pollinator-dependency, pollination deficit, fruit set, seed set, fruit quality 


\section{Introduction}

81

Pollinator-dependent crops comprise $75 \%$ of all major global food crop types and include some of the most valuable foodstuffs, both in terms of financial worth and nutritional content (Aizen et al., 2009; Chaplin-Kramer et al., 2014; Eilers et al., 2011; Klein et al., 2007). The degree to which pollinator-dependent crops rely on insect pollinators varies greatly, for example oilseed rape Brassica napus can receive an $18 \%$ yield boost when pollinated (Bommarco et al., 2012), strawberry Fragaria $\times$ ananassa yields can be increased by over 70\% (Hodgkiss et al., 2018), and macadamia Macadamia integrifolia yield can be up to $185 \%$ greater following insect pollination (Grass et al., 2018). Furthermore, pollination is known to also affect crop quality, including misshapes in pear Pyrus communis (Fountain et al., 2019), shelf life in strawberries (Klatt et al., 2014), commercial grade in apples (Garratt et al., 2014a), and oil content in oilseed rape (Bommarco et al., 2012). Concurrently, we have growing evidence that the dependence on insect pollination also varies between crop varieties, an effect that has been observed in oilseed rape (Hudewenz et al., 2014), strawberries (Klatt et al., 2014), blueberries Vaccinium corymbosum (Benjamin and Winfree, 2014), and apples (Garratt et al., 2016, 2014a).

Globally, the increasing production of pollinator-dependent crops drives the demand for pollination services (Aizen et al., 2019). However, documented declines in wild pollinator communities in some regions indicate a growing risk of pollination deficits (Aizen et al., 2008; Garibaldi et al., 2011; Potts et al., 2016b, 2016a; Winfree, 2008). To date, deficits have been documented in a number of fruit crops including apple (Garratt et al., 2014a), strawberry (Benjamin and Winfree, 2014), custard apple Annona reticulata (Pritchard and Edwards, 2006), and coffee Coffea arabica (Klein et al., 2003). Whilst a crop species or variety may always be pollinator-dependent, it is becoming clear that pollination deficits can vary in space and in time: improving our knowledge of where and when they 
occur, and to what extent they impact crop production, could help target efforts to manage pollination services. This will require robust and standardised methodology as well as local assessment and remediation (Garratt et al., 2019). Despite this, there has been relatively little research into the variability of different methods which are being used to determine pollinationdependence or deficits.

Pollinator exclusion is an example of an established method of quantifying crop dependence on pollinators (Delaplane et al., 2013). Mesh bags have been used to study pollinator-dependence in a number of crops, including coffee (Roubik, 2002; Steffan-Dewenter and Leschke, 2003), apples (Garratt et al., 2014b), strawberries (Klatt et al., 2014), and macadamia nuts (Grass et al., 2018). Conversely, pollination deficits (any shortfall in crop output due to a lack of pollination) can be quantified by giving flowers supplementary pollination and comparing production to that under open or ambient pollination. This is usually done by hand, using paintbrushes to transfer pollen from a suitable donor plant (Button and Elle, 2014; Garratt et al., 2016, 2014a; Hodgkiss et al., 2018; Hopping and Simpson, 1982; Hudewenz et al., 2014). In studies of tree crops, these manipulations have generally been carried out at the scale of the inflorescence or the branch (Fountain et al., 2019; Garratt et al., 2016, 2014a; Grass et al., 2018; Hopping and Simpson, 1982; Klein et al., 2003; Sheffield, 2014). However, by assessing pollination effects on only part of the plant, measured effects may not accurately reflect overall crop yield outcomes. This is because the allocation of resources to fruit depends on both the degree of pollination which the flower received, and the degree of pollination which the rest of the plant received: resource allocation and selective Stephenson, 1981).

This study aims to tests the standard methodology used in pollinator-dependence and pollination 
as a model crop. Apples are the most widely and commonly grown fruit crop in temperate regions, with 5,293,340 ha grown worldwide in 2016 (FAO, 2017). In the UK, apple production was estimated to be worth $f 141 \mathrm{~m}$ p.a. to the economy in 2016 . 'Gala' was the most common variety covering 2,110 ha, out of the total of 8,827 ha planted with dessert and culinary apple varieties (DEFRA, 2017). Apple flowers are grouped in inflorescences of approximately five flowers and the majority of apple flowers can set up to 10 seeds per fruit (Jackson, 2003). Most apple varieties are self-incompatible (Ramírez and Davenport, 2013) and in many modern orchards 'polliniser' trees are planted amongst the crop variety with the sole purpose of providing compatible pollen. Poor apple pollination and low seed set can reduce both yields (Garratt et al., 2014a; Stern et al., 2001) and fruit quality; leading to smaller fruit (Garratt et al., 2014a), increased asymmetry (Sheffield, 2014), and reduced mineral content (Volz et al., 1996). Fruit quality is a critical factor determining the value of apple crops and can have a significant impact on farm profitability (Garratt et al., 2014a).

In this paper, we test the hypotheses that: $(\mathrm{H} 1)$ greater biotic pollination improves fruitlet set and leads to higher yield at harvest, $(\mathrm{H} 2)$ observations of pollinator-dependence and pollination deficit are modified by the scale of experimentation, and $(\mathrm{H} 3)$ seed count is a viable indicator of apple fruit quality (e.g. size and shape).

\section{Methods}

\subsection{Study sites}

152 This study took place in 2014 and 2015 on a conventionally managed commercial fruit farm near Maidstone, Kent, England. Experiments were conducted in three apple orchard blocks, with each block managed as a separate unit. Four experimental plots were set up in each block. The plots were evenly spread through the blocks, at least $40 \mathrm{~m}$ away from each other, and at least $15 \mathrm{~m}$ away from the block edge. The trees used in the study were between four and eight years old and were the 
variety 'Gala', grafted onto 'M9' rootstocks. Tree spacing was $1 \mathrm{~m}$ within the row and $3.5 \mathrm{~m}$ between rows, with a polliniser tree planted after every 10 crop trees, at a ratio of 1:10. Polliniser trees were a mixture of crab apples (Malus spp.) and the apple variety 'Golden delicious'.

160

\subsection{Assessing pollination service and deficits at multiple scales}

Pollinator-dependence and pollination deficits were assessed at three experimental scales: the 'inflorescence', the 'branch', and the 'tree'. At each experimental scale, the pollinator-dependence and local pollination deficits of 'Gala' apples were assessed using three pollination treatments:

'closed' pollination (pollinator exclusion), 'open' pollination (where insects were free to visit flowers, representing business as usual), and 'supplementary' pollination (where insects were free to visit flowers, and additional pollination was carried out by hand). The pollinator exclusion treatments did not prevented wind pollination, but wind is not considered an important vector of apple pollen (Free, 1964). Pollination treatments were applied using methods adapted from Garratt et al. (2014a). The effects of the pollination treatments on fruitlet set, fruit set at harvest, and seed set were monitored at each scale.

In the first year, 2014, only inflorescence-scale effects were tested. Six trees were selected in each plot (72 trees spread across 12 plots and three blocks). Trees were separated from each other by at least 10 buffer trees within the row (a minimum of $10 \mathrm{~m}$ ) or one tree row $(7 \mathrm{~m})$. Before blossom, five inflorescences of a similar size and developmental stage, each on a different branch on the same side of the tree, were selected and randomly assigned to a pollination treatment. For the 'closed' treatment, PVC mesh bags with $1.2 \mathrm{~mm}^{2}$ diameter holes were used to cover two inflorescences per tree. These bags were removed once flowering had finished approximately three weeks later. Three more inflorescences were left 'open' to insect pollination, and one of these inflorescences received pollen from nearby polliniser trees: dehisced anthers were collected and shaken in a petri dish to 
release their pollen which was then applied fresh to all of the stigmas of target flowers using a fine paintbrush. Two inflorescences per tree were assigned to the 'closed' and 'open' treatments because fruit set was expected to be lower in these treatments and sufficient numbers of apples were needed for fruit quality analysis. Each inflorescence was tagged with a coloured marker to denote the treatment and the number of flowers present was recorded. In all, 360 inflorescences were monitored in 2014.

In 2015, the same plots were used to expand the experiment to investigate different scales. The inflorescence-scale experiment from 2014 was repeated on one tree per plot (36 inflorescences over 12 trees in total). Three separate trees per plot were each assigned a branch scale treatment (12 replicates per treatment, 36 branches in total) and a further three trees per plot were assigned a tree-scale treatment (12 replicates per treatment, 36 trees in total). In each plot, trees were chosen using the same spacing as the previous year and were then randomly assigned to both scales and treatments. For the 'closed' or pollinator excluded treatment, 'branches' were covered with mosquito netting with $2.2 \mathrm{~mm}^{2}$ diameter holes, and 'trees' were covered with commercially available mosquito nets of the same material measuring $2.6 \mathrm{~m}$ high and with a base diameter of 2.6 $\mathrm{m}$. Netting and nets were removed along with the inflorescence bags at the end of blossom period in mid-May. 'Supplementary' hand pollination of the trees was carried out up to a height of $3 \mathrm{~m}$. For the majority of the trees this included all flowers in bloom; however for some trees a small proportion of flowers at the top did not receive hand pollination. For all experimental scales, hand pollination was carried out during a single visit at peak blossom: all flowers in bloom received supplementary pollination whilst flowers with unopened petals did not receive supplementary pollination.

The three experimental scales varied considerably in the number of flowers which they contained: the single 'inflorescence' scale treatments had a mean of $5.7 \pm 0.2$ flowers; the 'branches' had $6.9 \pm$ 

an estimated $741.4 \pm 29.3$ flowers. Flower numbers for whole trees were estimated by counting the number of inflorescences and multiplying by the average number of flowers seen per inflorescence in the 'inflorescence' scale and 'branch' scale treatments (5.55 \pm 0.02$)$.

Three different measures of pollination service and deficit were recorded for all treatments: fruitlet set, fruit set at harvest, and seed set. Fruitlet set was recorded approximately four weeks after blossom had ended. Fruit set at harvest was recorded approximately one week before commercial harvest took place. Seed set was also determined at this time: all fruit from the 'inflorescence' and 'branch' scale pollination treatments were collected along with a randomly selected subset of five fruit from each of the 'tree' scale pollination treatments. The number of seeds which had set in these fruit was then recorded. In this part of the study 396 'inflorescences' (360 from 2014 and 36 from 2015), 36 'branches' (with 247 inflorescences), and 36 'trees' (with 4,697 inflorescences) were monitored. A total of 283, 194, and 175 apples were collected for seed set counts respectively. Data from 2014 and 2015 were combined for analysis.

\subsection{Seed set as a rapid metric of pollination}

A separate analysis, in parallel to the pollinator dependence and deficit experiments, was conducted to test if seed set can be used as a rapid metric of pollination and fruit quality. To increase the power of the statistical analysis, seed set and fruit quality data from fruit collected during the pollination experiment were combined with data from other fruit harvested from the same blocks. In total, 3,196 fruit were included in this analysis; 652 from the pollination experiment described above and an additional 2,544 fruit. All additional fruit were 'Gala' apples collected from the same 3 study blocks at the same time as those from the pollination experiment. Fruit quality measures included: seed number, fresh mass, diameter, height, firmness (using a Silverline penetrometer), sugar content or Brix (using a Hanna refractometer), dry mass (entire fruit were cut into four pieces and 
oven dried at $70^{\circ} \mathrm{C}$ for at least 72 hours before weighing), and defects (scored using industry standards as either minimal, moderate, or excessive for defects in shape or development). Not all fruit quality measures were recorded for all fruit: dry mass was not measured for the fruit in the 2014 inflorescence pollination experiment, Brix and firmness were not measured for the branch or tree scale pollination treatments, and height was not measured for the fruit which was not part of the pollination experiment.

Apples were assigned commercial grades based on standards produced by the Food and Agriculture Organisation (UN) standards (FAO, 2010), where fruit must be greater than $60 \mathrm{~mm}$ in diameter or 90 $\mathrm{g}$ in mass, or must exceed $10.5^{\circ}$ Brix and not be smaller than $50 \mathrm{~mm}$ or $70 \mathrm{~g}$. Fruit which fulfilled all of these criteria with only minimal defects were scored as 'Class 1', fruit which fulfilled the criteria with moderate defects were scored as 'Class 2', and finally fruit which failed at least one criterion or which displayed excessive defects were scored as 'Class 3', commonly considered unmarketable as dessert fruit. Colour was not included as a quality measure as it is thought to be largely determined by light exposure (Corelli-Grappadelli, 2003).

250

\subsection{Statistical analysis}

Data were analysed with linear mixed models and generalised linear mixed models (GLMMs) in R ( Core Team, 2017) using the "Ime4" (Bates et al., 2012) and "glmmADMB" (Fournier et al., 2012) packages.

Separate GLMMs were created for each experimental scale to test how pollination treatment affected the different measures of pollination service and deficit. Fruitlet set was analysed as a twocolumn integer matrix containing the number of flowers (at the relevant experimental scale) which developed into fruitlets compared to the number which failed to set. Fruit set at harvest was analysed as a two-column integer matrix containing the number of flowers (at the relevant 
experimental scale) which produced fruit still present at harvest compared to the number which failed to do so. Seed set was analysed as a count of seed numbers. Pollination treatment was the main fixed effect in all of these models and the random effects were: tree, nested within plot, nested within block. Year of harvest was included as a fixed effect for the inflorescence scale models to account for variations between 2014 and 2015. Observation-level random effects were added to reduce overdispersion in the fruitlet set, fruit at harvest, and seed set models for the tree scale and for the fruit at harvest model for the branch scales (Harrison, 2014). Error families were binomial for the fruitlet set and fruit set at harvest models, Poisson for the inflorescence and branch scale seed set models, and negative binomial for the tree scale seed set model.

Separate GLMMs were also created to test how the different experimental scales affected the results from within the same pollination treatments. Here, the data were modelled with separate GLMMs with treatment scale as the main fixed effect. Error families were either binomial or Poisson, and random effects were used as above apart from observation-level random effect which was included for the 'excluded' pollination treatment to reduce overdispersion.

The effect of seed number on fruit quality measures and class was assessed using linear mixed model regressions. Each fruit quality measure was modelled separately with seed number as the main fixed effect and tree nested within plot, and block as random effects. The block of origin and the year of harvest were included as crossed random effects.

\section{Results}

\subsection{Levels of service and deficits}

Manipulating pollination levels showed that more pollination resulted in greater fruitlet set, fruit set at harvest, and seed set at every experimental scale (Fig. 1), although these results were not 
statistically significant at every scale (Table 1). Grand means of the pollination treatments at all three experimental scales showed that, when compared to the 'open' treatments, fruitlet set decreased to $54.9 \%$ when pollinators were excluded and increased to $207 \%$ with supplementary pollination. By harvest time, fruit set was 55\% of 'open' pollination levels following pollinator exclusion and $167 \%$ with additional hand pollination. Seed set showed a similar trend: pollinator exclusion resulted in just $23 \%$ of 'open' treatment seed numbers whilst supplementary pollination lead to a grand mean of $150 \%$.

\subsection{Effects of experimental scale}

There were statistically significant differences between the different experimental scales (Table 2). Fruitlet set was significantly lower in the 'excluded' treatment at the 'inflorescence' scale (22\%) when compared to the same treatment at the branch (73\%) and tree (65\%) scales, suggesting lower flower fertilisation, or possibly more selective fruitlet setting. Supplementary pollination also showed significant differences in the number of fruitlets between all three scales, with $341 \%$ at the inflorescence scale, $174 \%$ at the branch scale, and $125 \%$ at the tree scale (Table 2 ).

302

Fruit set at harvest was significantly lower at the 'inflorescence' scale than at the 'branch' and 'tree' scales when pollinators were excluded: $13 \%, 75 \%$, and $79 \%$ respectively (Table 2 ). The 'inflorescence' scale also showed a significantly greater effect of supplementary pollination: $218 \%$, $172 \%$, and $117 \%$ respectively.

Seed set was significantly higher in the supplementary pollination treatment at the 'inflorescence' scale than at the 'branch' or 'tree' scales: 193\%, 123\%, and 135\% respectively (Table 2). This indicates that a greater proportion of flowers per inflorescence were receptive at the time of hand pollination compared to branches and trees: flowering is not completely synchronous within the 
inflorescence or within the tree. Seed set did not differ significantly in the excluded treatments: $11 \%$ at inflorescence, $27 \%$ at branch, and $31 \%$ at tree scales (Table 2 ).

Fruitlet set following supplementary pollination was the only measurement which produced a harvest, and seed set did not differ significantly between the different experimental scales in the 'open' treatment. At the 'inflorescence' scale, models indicated no Year effect on fruitlet set or fruit set at harvest, but a significant effect was seen in the seed set model.

\subsection{Seed set as a rapid indicator of pollination deficit}

Fruit with higher seed number had a significantly greater diameter, height, fresh mass, and dry mass, though the effects were slight (Fig. 2). Fruit firmness was not affected by seed number, while sugar content showed a significant though slight trend for lower sweetness with more seeds. Seed set had a significant positive effect on fruit class, the key deciding factor of a fruits value (Fig. 3).

\section{Discussion}

The first aim of the study was to quantify pollinator-dependence and possible pollination deficits in a key crop; 'Gala' apple. Insect pollination was highly beneficial to both yield (fruit set at harvest) and quality. A grand mean of the experimental scales showed that when pollinators were excluded yields fell to $55 \%$ of open, ambient pollination. Pollination deficits were also shown to exist in the study orchards; supplementary pollination resulted in a grand mean yield which was $167 \%$ of open pollination alone. Supplementary pollination also resulted in increased seed set, with seed numbers at $150 \%$ of current pollination levels when averaged across the experimental scales. The positive trend of increased pollination on fruitlet set, fruit set at harvest, and seed set was seen at all three experimental scales. 
The second aim of the study was to test how experimental scale affects the results of pollinatordependence and pollination deficit experiments. Although the general trends of the effects of pollination were the same, the results show that the negative effects of experimentally reduced pollination and the positive effects of supplementary pollination diminish at a larger scale of observation. Some of the many reasons for this effect, including biological, crop management, and methodological, are discussed below.

A biological process which may contribute to this variation is the capacity of apple trees to selectively abscise fruit (Dennis et al., 2003), thus compensating for the effects of poor pollination on experimental branches. Fruitlets are more likely to be abscised if poorly pollinated (Dennis et al., 2003), however if a plant has a low overall fruit set, the chances of abscission are reduced (Jackson, 2003; Stephenson, 1981). The 'June drop' is a period of roughly four to six weeks after blossom, when trees abscise a proportion of their fruitlets, often those which have received insufficient pollination and have low seed-set (Gucci et al., 1991; Jackson, 2003). The proportion of the fruit which undergoes this process is thought to depend on the level of pollination received by the tree as a whole, the resources within a tree, and the weather (Bangerth, 2000; Stephenson, 1981). The representativeness of pollination observations at different scales will therefore differ: if a single inflorescence is poorly pollinated, it will have less of an effect on the plant's overall abscission rate than if an entire branch had received poor pollination, and less effect still when compared to the entire tree. In other words, due to adaptive abscission, the likelihood of an unpollinated flower producing a fruit would be lower if it was on an un-pollinated inflorescence, than if the same flower was on an unpollinated branch, and lower still than if it was on an unpollinated tree, because the overall chance of abscission is lower at greater scales due to the tree's ability to adapt to low overall seed fertilisation. 
Managing fruitlet numbers through artificial thinning will also affect the proportion and size of fruit at harvest. Thinning is carried out to create an optimal crop load: stopping a tree's resources being wasted on overly small or misshapen fruit, reducing the risk of branches breaking due to heavy fruit loads, and preventing biennial cropping, where trees enter boom-bust cycles of production which can reduce overall yields and make output unreliable (Byers et al., 2003; Jonkers, 1979). Because hand thinning focuses on smaller, less well formed fruit, which previous studies suggest are more likely to have low seed numbers (Garratt et al., 2014a, 2014b), it may lead to an underestimate of the influence of pollination on fruit quality as this fruit is less likely to reach harvest and be assessed for quality. Both the thinning process and the natural abscission of fruit are likely to have a moderating effect on extremes of pollination, and may explain some of the differences observed between the treatment effects at different scales. It is also possible that high fruit set could result in increased thinning costs, particularly in varieties which are considered to be heavy cropping, such as 'Gala', and any financial assessment should take this into account. The variation seen between initial fruit set and fruit set at harvest highlights the importance of monitoring the effects of pollination experiments through to harvest: measuring initial fruit set alone and assuming this is directly related to final yield would have resulted in the overestimation of the effects of the pollination treatment on crop production (Bos et al., 2007).

There are also several methodological reasons which may partially explain the differences in results between experimental scales. Excluding pollinators from large trees and those with wire supports is practically difficult, whole-tree nets are likely to be less effective at excluding pollinators entirely than the methods used for inflorescences or branches due to the greater potential for gaps in the netting or insects being trapped inside it. Supplementary pollination at larger scales is also logistically more difficult, the unequal development times of flowers on a tree together with their potential inaccessibility means that supplementary hand pollination may not be uniform at larger scales. In this study, only one round of hand pollination was conducted and some flowers on the tree 
scale and branch scale experiments may not have been pollinated, resulting in an inaccurate representation of maximum pollination. This could be remedied by repeated rounds of supplementary pollination, but as the scale of the experiment and the number of flowers increases so does the need for additional rounds of supplementary pollination in order to catch all flowers when they are receptive. Repeated rounds of supplementary pollination on larger scales also increase the risk of repeated pollination of the same flower, leading to potential damage and yield reduction (Sáez et al., 2014).

The variation in results between the different experimental scales is important because it shows that choice of scale can affect the conclusions of a study, and may therefore influence orchard management decisions informed by the findings. Many previous studies which have looked at pollination of larger crop plants, particularly tree crops, have used individual inflorescences as their sample units (Fountain et al., 2019; Garratt et al., 2016, 2014a; Grass et al., 2018; Hopping and Simpson, 1982; Klein et al., 2003; Sheffield, 2014), and while assessments at smaller scales may accurately reflect relative differences in levels of pollination and are more likely to reflect a true pollination maximum in the supplementary pollination treatments, our results show that this approach may lead to an overestimation of pollinator-dependence and pollination deficits due to the biological and crop management factors discussed. This is particularly pertinent if there is a specific threshold of deficit at which pollination management decisions are triggered, e.g. bringing in additional honeybee hives. Although the relationships between pollination and apple yield were common amongst all scales tested in this study, larger scale measurements of pollination service may be better at capturing the effects of adaptive abscission and artificial thinning. Taking methodological limitations into account, and given that the branch scale experiment was only significantly different from the tree scale experiment in one measure: fruitlet set in the supplementary pollination treatment, it seems that experiments run at this scale capture much of the benefits of conducting pollinator-dependence experiments at the whole-plant scale whilst 
suffering from fewer methodological challenges with effective pollinator exclusion and supplementary pollination. For future research into the effects of pollination on crops it is necessary to consider both the accuracy with which different experimental scales will reflect true production dependence and deficits, and the practical limitations of conducting experiments at different scales. This is particularly important if rapid assessments of pollination service across multiple locations are required (Garratt et al., 2019). Based on the results of this study, we recommend that pollinatordependence and pollination deficit measurements should be carried out at the largest feasible scale, particularly if effects on final crop production are to be assessed. For tree crops, it may not be possible to manipulate the whole plant effectively, in which case the branch is recommended as an appropriate unit size.

The third aim of the study was to assess the effect of seed set on fruit quality and to determine whether seed set could be used as a rapid measure of a crop's pollinator-dependence and pollination deficit, considering the time and resources necessary for effective pollinator exclusion and supplementary pollination. Greater seed set was shown to have a positive effect on several measures of fruit quality and increased the proportion of Class 1 fruit being produced. These results concur with those of a number of other studies and further highlight the importance of pollination services to apple production (Garratt et al., 2014a, 2014b; Ladurner et al., 2004; Sheffield, 2014). Fruit quality is a key determinant of a crop's worth, with Class 1 fruit achieving a significant premium (Garratt et al., 2014a). The improvements in fruit size and mass and the higher proportions of Class 1 fruit seen with increasing seed numbers shows that pollination is important for quality as well as

437 yields. Fruit morphology is effected by seeds not only in terms of how many seeds there are but also how they are distributed amongst the carpels; unbalanced seed distribution may result in malformation (Brault and de Oliveira, 1995; Sheffield, 2014). More thorough pollination, with repeated visitation and visitation from different pollinator taxa, may help to ensure more comprehensive fertilisation (Sapir et al., 2017; Stern et al., 2001). We recommend that growers 
record seed set as part of their routine monitoring of fruit quality and development as this will give an indication of pollination levels in their orchards and may alert them to potential deficits. Whilst resource allocation and adaptive abscission may help to reduce the impact of poor pollination there is little that can be done to recover production in a year when low seed set and low fruit set occur.

In conclusion, insect pollination was shown to be highly important for 'Gala' yield and quality. There was a strong trend showing increased pollination resulting in improved production, at all experimental scales. However, the extent to which pollination was found to affect production depended on the experimental scale at which it was measured. It is recommended that pollination manipulation experiments are carried out at the largest scale feasible and caution should always be exercised when extrapolating from experimental units to large scale crop production (see Vaissière, Freitas \& Gemmill-Herren 2011). For tree crops such as apple, the branch appears to be a suitable scale as it balances biological and crop management factors with methodological limitations. Crop pollination experiments should also measure treatment effects through to harvest if effects on production are to be estimated, as using initial fruit set may lead to the overestimation of effect size. Seed set was shown to be a good indicator of crop quality and of crop value and it is recommended that seeds are counted as part of growers' crop quality monitoring programmes to highlight potential pollination deficits.

\section{Acknowledgements}

462

This research was funded by the Biotechnology and Biological Sciences Research Council and Sainsbury's Supermarkets Ltd (BB/K012843/1). We would like to thank the directors and staff of AC Goatham and Son for their participation and use of their orchards. Part of this research was conducted with and alongside the DEFRA funded National Pollinator and Pollination Monitoring Framework (WC1101) project. 


\section{References}

470

Aizen, M.A., Aguiar, S., Biesmeijer, J.C., Garibaldi, L.A., Inouye, D.W., Jung, C., Martins, D.J., Medel, R., Morales, C.L., Ngo, H., Pauw, A., Paxton, R.J., Sáez, A., Seymour, C.L., 2019. Global agricultural productivity is threatened by increasing pollinator dependence without a parallel increase in crop diversification. Glob. Chang. Biol. 25, 3516-3527. https://doi.org/10.1111/gcb.14736

Aizen, M.A., Garibaldi, L.A., Cunningham, S.A., Klein, A.M., 2009. How much does agriculture depend on pollinators? Lessons from long-term trends in crop production. Ann. Bot. 103, 1579-1588.

Aizen, M.A., Garibaldi, L.A., Cunningham, S.A., Klein, A.M., 2008. Long-term global trends in crop https://doi.org/10.1093/aob/mcp076

\section{Aizen, M.A., Garibaldi, L.A., Cunningham, S.A., Klein, A.M., 2008. Long-term global trends in crop} yield and production reveal no current pollination shortage but increasing pollinator dependency. Curr. Biol. 18, 1572-1575. https://doi.org/10.1016/j.cub.2008.08.066

Bangerth, F., 2000. Abscission and thinning of young fruit and their regulation by plant hormones and bioregulators 43-59.

Bates, D., Mächler, M., Bolker, B., 2012. Fitting linear mixed-effects models using Ime4. J. Stat. Softw. 67, 51. https://doi.org/10.18637/jss.v067.i01.

Benjamin, F.E., Winfree, R., 2014. Lack of pollinators limits fruit production in commercial blueberry (Vaccinium corymbosum). Environ. Entomol. 43, 1574-1583. https://doi.org/10.1603/EN13314

Bommarco, R., Marini, L., Vaissière, B.E., 2012. Insect pollination enhances seed yield, quality, and market value in oilseed rape. Oecologia 169, 1025-1032. https://doi.org/10.1007/s00442-012$2271-6$

Bos, M.M., Veddeler, D., Bogdanski, A.K., Klein, A.M., Tscharntke, T., Steffan-Dewenter, I., Tylianakis, J.M., 2007. Caveats to quantifying ecosystem services: Fruit abortion blurs benefits from crop pollination. Ecol. Appl. 17, 1841-1849. https://doi.org/10.1890/06-1763.1 
Brault, A.M., de Oliveira, D., 1995. Seed number and an asymmetry index of 'McIntosh ' apples. HortScience 30, 44-46.

Button, L., Elle, E., 2014. Wild bumble bees reduce pollination deficits in a crop mostly visited by managed honey bees. Agric. Ecosyst. Environ. 197, 255-263. https://doi.org/10.1016/j.agee.2014.08.004

Byers, R.E., Ferree, D.C., Warrington, I.J., 2003. Apples: botany, production and uses. CABI, Wallingford. https://doi.org/10.1079/9780851995922.0000

Chaplin-Kramer, R., Dombeck, E., Gerber, J., Knuth, K.A., Mueller, N.D., Mueller, M., Ziv, G., Klein, A.M., 2014. Global malnutrition overlaps with pollinator-dependent micronutrient production. Proc. R. Soc. B Biol. Sci. 281, 20141799. https://doi.org/10.1098/rspb.2014.1799

Corelli-Grappadelli, L., 2003. Light Relations. Apples Bot. Prod. Uses 195-216. https://doi.org/10.1079/9780851995922.0195

DEFRA, 2017. Horticulture Statsistics, https://www.gov.uk/government/statistics/horticulturestatistics-2016 [WWW Document]. Hortic. Stat.

Delaplane, K.S., Dag, A., Danka, R.G., Freitas, B.M., Garibaldi, L.A., Goodwin, R.M., Hormaza, J.I., 2013. Standard methods for pollination research with Apis mellifera. J. Apic. Res. 52, 1-28. https://doi.org/10.3896/ibra.1.52.4.12

Dennis, F.J., Ferree, D.C., Warrington, I.J., 2003. Apples: botany, production and uses. CABI, Wallingford. https://doi.org/10.1079/9780851995922.0000

Eilers, E.J., Kremen, C., Greenleaf, S.S., Garber, A.K., Klein, A.M., 2011. Contribution of pollinatormediated crops to nutrients in the human food supply. PLoS One 6, e21363. https://doi.org/10.1371/journal.pone.0021363

FAO, 2017. FAOSTAT Crop Data, http://www.fao.org/faostat/en/\#data/QC [WWW Document]. FAO, 2010. Standard for apples CODEX STAN 73-1981.

Fountain, M.T., Mateos-Fierro, Z., Shaw, B., Brain, P., Delgado, A., 2019. Insect pollinators of conference pear (Pyrus communis L.) and their contribution to fruit quality. J. Pollinat. Ecol. 25, 
Fournier, D., Skaug, H., Ancheta, J., lanelli, J., Magnusson, A., Maunder, M., Nielsen, A., Sibert, J., 2012. AD Model Builder: using automatic differentiation for statistical inference of highly parameterized complex nonlinear models. Optim. Methods Softw. 27, 233-249.

Free, J.B., 1964. Comparison of the importance of insect and wind pollination of apple trees. Nature 201, 726-727. https://doi.org/10.1038/201726b0

Garibaldi, L.A., Aizen, M.A., Klein, A.M., Cunningham, S.A., Harder, L.D., 2011. Global growth and stability of agricultural yield decrease with pollinator dependence. Proc. Natl. Acad. Sci. U. S. A. 108, 5909-14. https://doi.org/10.1073/pnas.1012431108

Garratt, M.P.D., Breeze, T.D., Boreux, V., Fountain, M.T., McKerchar, M., Webber, S.M., Coston, D.J., Jenner, N., Dean, R., Westbury, D.B., Biesmeijer, J.C., Potts, S.G., 2016. Apple pollination: Demand depends on variety and supply depends on pollinator identity. PLoS One 11, 1-15. https://doi.org/10.1371/journal.pone.0153889

Garratt, M.P.D., Breeze, T.D., Jenner, N., Polce, C., Biesmeijer, J.C., Potts, S.G., 2014a. Avoiding a bad apple: Insect pollination enhances fruit quality and economic value. Agric. Ecosyst. Environ. 184, 34-40. https://doi.org/http://dx.doi.org/10.1016/j.agee.2013.10.032

Garratt, M.P.D., Potts, S.G., Banks, G., Hawes, C., Breeze, T.D., O’Connor, R.S., Carvell, C., 2019. Capacity and willingness of farmers and citizen scientists to monitor crop pollinators and pollination services. Glob. Ecol. Conserv. 20, e00781. https://doi.org/10.1016/j.gecco.2019.e00781

Garratt, M.P.D., Truslove, C.L., Coston, D.J., Evans, R.L., Moss, E.D., Dodson, C., Jenner, N., Biesmeijer, J.C., Potts, S.G., 2014b. Pollination deficits in UK apple orchards. J. Pollinat. Ecol. 12, 9-14.

Grass, I., Meyer, S., Taylor, P.J., Foord, S.H., Hajek, P., Tscharntke, T., 2018. Pollination limitation despite managed honeybees in South African macadamia orchards. Agric. Ecosyst. Environ. 260, 11-18. https://doi.org/10.1016/j.agee.2018.03.010 
Gucci, R., Mazzoleni, S., Dennis, F.G., 1991. Effect of fruit wounding and seed removal on abscission of apple fruit between June drop and harvest. New Zeal. J. Crop Hortic. Sci. 19, 79-85. https://doi.org/10.1080/01140671.1991.10421784

Harrison, X.A., 2014. Using observation-level random effects to model overdispersion in count data in ecology and evolution. PeerJ 2, e616. https://doi.org/10.7717/peerj.616

Hodgkiss, D., Brown, M.J.F., Fountain, M.T., 2018. Syrphine hoverflies are effective pollinators of commercial strawberry. J. Pollinat. Ecol. 22, 55-66. https://doi.org/10.26786/19207603(2018)five

Hopping, M.E., Simpson, L.M., 1982. Supplementary pollination of tree fruits. New Zeal. J. Agric. Res. 25, 245-250. https://doi.org/10.1080/00288233.1982.10420919

Hudewenz, A., Pufal, G., Bögeholz, A.L., Klein, A.M., 2014. Cross-pollination benefits differ among oilseed rape varieties. J. Agric. Sci. 152, 770-778. https://doi.org/10.1017/S0021859613000440 Jackson, J.E., 2003. Biology of Apples and Pears. Cambridge University Press, Cambridge. Jonkers, H., 1979. Biennial bering in apple and pear: a literature survey. Sci. Hortic. (Amsterdam). 11, 303-317. https://doi.org/10.1016/0304-4238(79)90015-3

Klatt, B.K., Holzschuh, A., Westphal, C., Clough, Y., Smit, I., Pawelzik, E., Tscharntke, T., 2014. Bee pollination improves crop quality, shelf life and commercial value. Proc. R. Soc. B Biol. Sci. 281, 20132440. https://doi.org/10.1098/rspb.2013.2440

Klein, A.M., Steffan-Dewenter, I., Tscharntke, T., Steffan-Dewenter, I., Tscharntke, T., 2003. Fruit set of highland coffee increases with the diversity of pollinating bees. Proc. R. Soc. London. Ser. B Biol. Sci. 270, 955-961. https://doi.org/10.1098/rspb.2002.2306

Klein, A.M., Vaissiere, B.E., Cane, J.H., Steffan-Dewenter, I., Cunningham, S.A., Kremen, C., Tscharntke, T., 2007. Importance of pollinators in changing landscapes for world crops. Proc. R. Soc. B Biol. Sci. 274, 303-313.

Ladurner, E., Recla, L., Wolf, M., Zelger, R., Burgio, G., 2004. Osmia cornuta (Hymenoptera Megachilidae) densities required for apple pollination: a cage study. J. Apic. Res. 43, 118-122. 
Potts, S.G., Imperatriz-Fonseca, V., Ngo, H.T., Aizen, M.A., Biesmeijer, J.C., Breeze, T.D., Dicks, L. V., Garibaldi, L.A., Hill, R., Settele, J., Vanbergen, A.J., 2016a. Safeguarding pollinators and their values to human well-being. Nature 540, 220-229. https://doi.org/10.1038/nature20588

Potts, S.G., Imperatriz-Fonseca, V., Ngo, H.T., Biesmeijer, J.C., Breeze, T.D., Dicks, L. V., Garibaldi, L.A., Hill, R., Settele, J., Vanbergen, A.J., Aizen, M.A., Cunningham, S.A., Eardley, C., Freitas, B.M., Gallai, N., Kevan, P.G., Kovács-Hostyánszki, A., Kwapong, P.K., Li, J., Li., X., Martins, D.J., Nates-Parra, G., Pettis, J.S., Rader, R., Viana, B.F., 2016b. IPBES: Summary for policymakers of the assessment report of the Intergovernmental Science-Policy Platform on Biodiversity and Ecosystem Services on pollinators, pollination and food production, IPBES. Secretariat of the Intergovernmental Science-Policy Platform on Biodiversity and Ecosystem Services, Bonn, Germany. https://doi.org/10.1007/s00442-010-1809-8

Pritchard, K.D., Edwards, W., 2006. Supplementary pollination in the production of custard apple (Annona sp.) - the effect of pollen source. J. Hortic. Sci. Biotechnol. 81, 78-83. https://doi.org/10.1080/14620316.2006.11512032

R Core Team, 2017. R: A language and environment for statistical computing. R Foundation for Statistical Computing, Vienna, Austria.

Ramírez, F., Davenport, T.L., 2013. Apple pollination: A review. Sci. Hortic. (Amsterdam). 162, 188203. https://doi.org/http://dx.doi.org/10.1016/j.scienta.2013.08.007

Roubik, D.W., 2002. Tropical agriculture: The value of bees to the coffee harvest. Nature 417, 708708. https://doi.org/10.1038/417708a

Sáez, A., Morales, C.L., Ramos, L.Y., Aizen, M.A., 2014. Extremely frequent bee visits increase pollen deposition but reduce drupelet set in raspberry. J. Appl. Ecol. 51, 1603-1612. https://doi.org/10.1111/1365-2664.12325

Sapir, G., Baras, Z., Azmon, G., Goldway, M., Shafir, S., Allouche, A., Stern, E., Stern, R.A., 2017. Synergistic effects between bumblebees and honey bees in apple orchards increase cross pollination, seed number and fruit size. Sci. Hortic. (Amsterdam). 219, 107-117. 
599

600

601

602

603

604

605

606

607

608

609

610

611

612

613

614

615

616

617

618

619

620

621

622

623

Sheffield, C.S., 2014. Pollination, seed set and fruit quality in apple: studies with Osmia lignaria (Hymenoptera: Megachilidae) in the Annapolis Valley, Nova Scotia, Canada. J. Pollinat. Ecol. 12, 120-128. https://doi.org/10.3390/molecules14041513

Steffan-Dewenter, I., Leschke, K., 2003. Effects of habitat management on vegetation and aboveground nesting bees and wasps of orchard meadows in Central Europe. Biodivers. Conserv. 12, 1953-1968. https://doi.org/10.1023/A:1024199513365

Stephenson, A.G., 1981. Flower and fruit abortion: proximate causes and ultimate functions. Annu. Rev. Ecol. Syst. 12, 253-279. https://doi.org/10.1146/annurev.es.12.110181.001345

Stern, R.A., Eisikowitch, D., Dag, A., 2001. Sequential introduction of honeybee colonies and doubling their density increases cross-pollination, fruit-set and yield in "Red Delicious" apple. J. Hortic. Sci. Biotechnol. 76, 17-23.

Vaissière, B., Freitas, B., Gemmill-Herren, B., 2011. Protocol to detect and assess pollination deficits in crops: a handbook for its use, Pollination services for sustainable agriculture. FAO, Rome.

Volz, R.K., Tustin, D.S., Ferguson, I.B., 1996. Pollination effects on fruit mineral composition, seeds and cropping characteristics of 'Braeburn' apple trees. Sci. Hortic. (Amsterdam). 66, 169-180. https://doi.org/http://dx.doi.org/10.1016/S0304-4238(96)00934-X

Winfree, R., 2008. Pollinator-dependent crops: an increasingly risky business. Curr. Biol. 18, 968969. https://doi.org/10.1016/j.cub.2008.09.010 7 8

9




\section{Cover image}

625

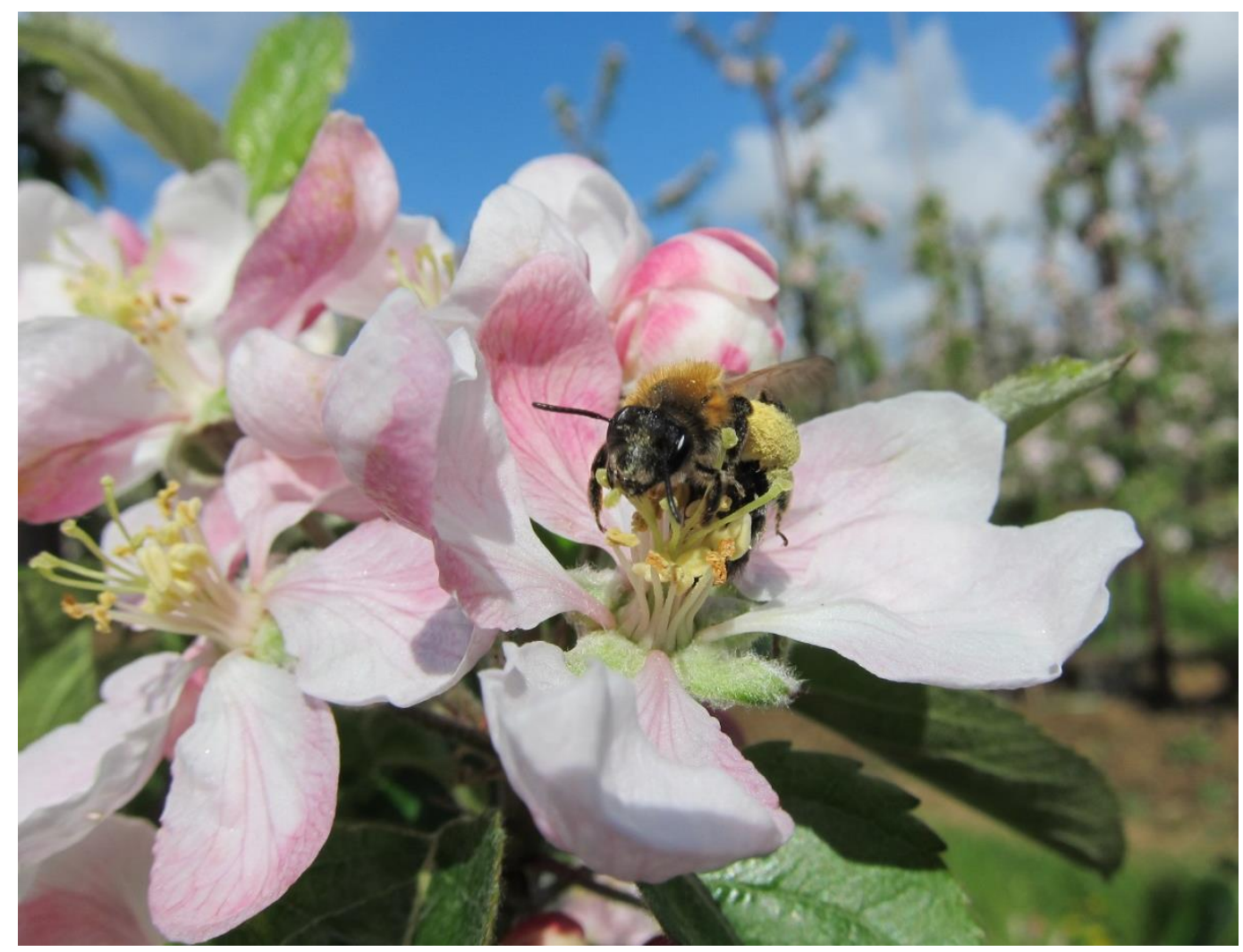

626

(Andrena sp. foraging on 'Gala' apple flowers)

627 
628

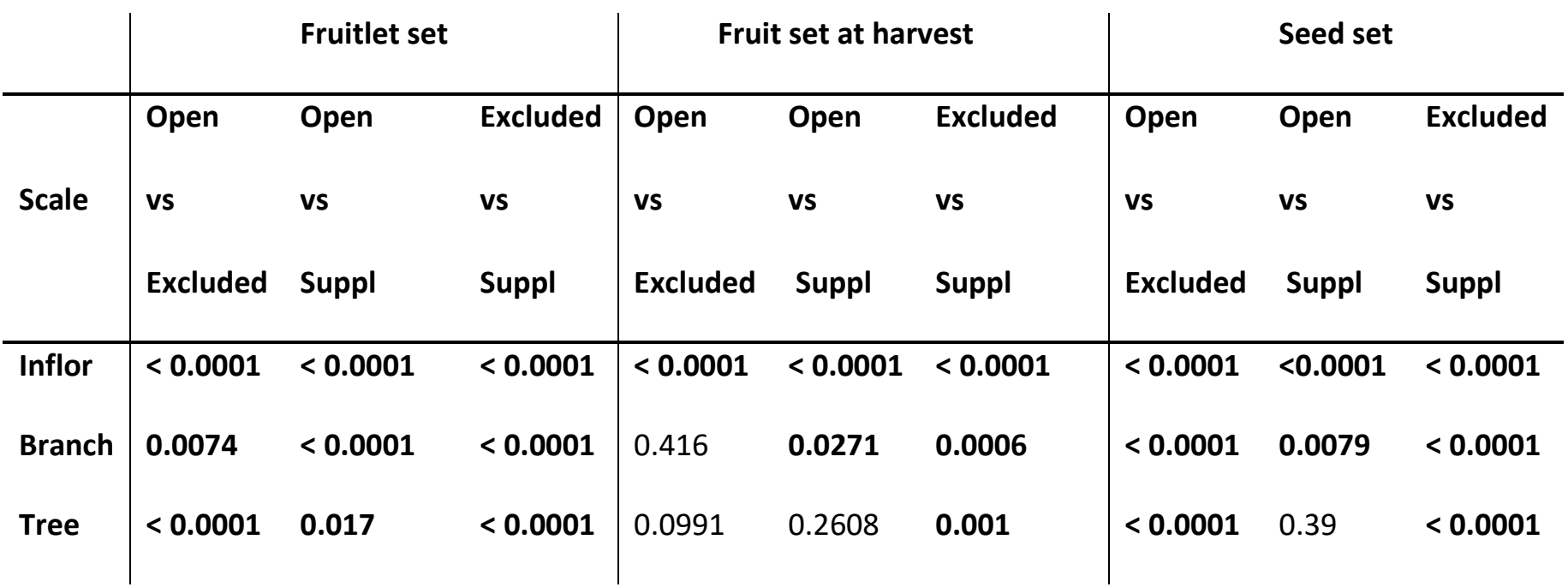

Table 1. $P$-values of least square means test comparing the effects of pollination treatments on fruitlet set, fruit set at harvest, and seed set at three experimental scales. "Inflor" = inflorescence, "Suppl" = supplementary pollination. The treatment with the greater level of pollination (Supplementary > Open > Excluded) produced the highest result in all cases. Based on data from 2014 and 2015. 


\begin{tabular}{|c|c|c|c|c|c|c|c|c|c|}
\hline & \multicolumn{3}{|c|}{ Fruitlet set } & \multicolumn{3}{|c|}{ Fruit set at harvest } & \multicolumn{3}{|c|}{ Seed set } \\
\hline \multirow{3}{*}{ Treatment } & Inflor & Inflor & Branch & Inflor & Inflor & Branch & Inflor & Inflor & Branch \\
\hline & vs & vs & vs & vs & vs & vs & vs & vs & vs \\
\hline & Branch & Tree & Tree & Branch & Tree & Tree & Branch & Tree & Tree \\
\hline Excluded & $<0.0001$ & $<0.0001$ & 0.1813 & $<0.0001$ & $<0.0001$ & 0.3402 & 0.0840 & 0.1597 & 0.8577 \\
\hline Open & 0.2160 & 0.5163 & 0.7872 & 0.8483 & 0.7716 & 0.5245 & 0.9226 & 0.9410 & 0.9980 \\
\hline Suppl & $<0.0001$ & $<0.0001$ & 0.0001 & 0.0094 & $<0.0001$ & 0.2409 & $<0.0001$ & $<0.0001$ & 0.7388 \\
\hline
\end{tabular}

637

Table 2. $P$-values of least square means tests comparing the effects of pollination treatments between experiments conducted at different scales. "Inflor" = 

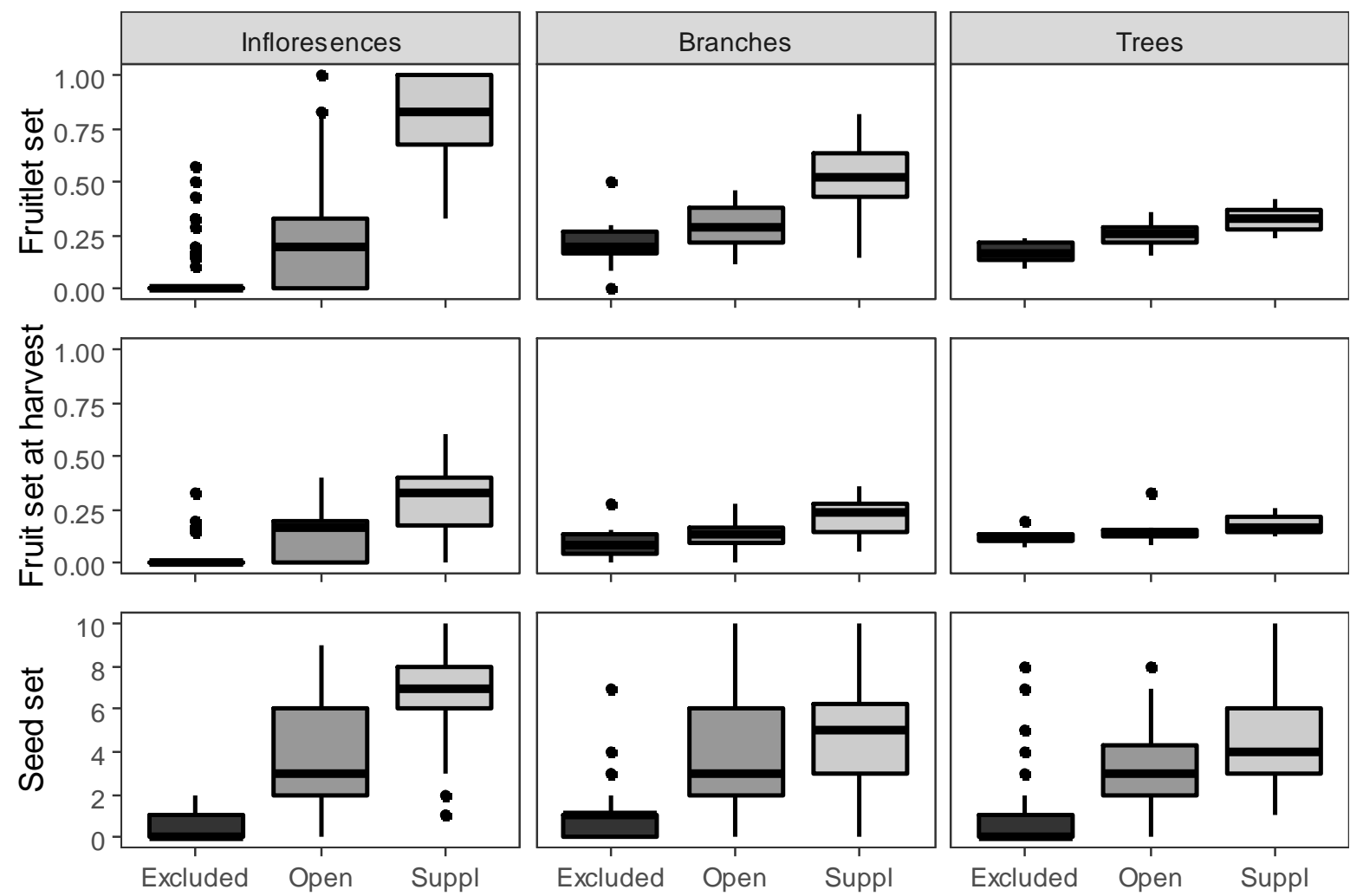

Excluded Open Suppl Pollination treatment

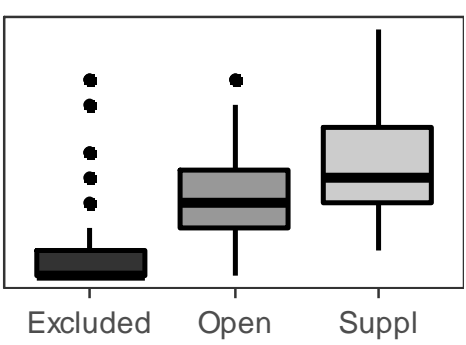

641

Figure 1. Pollination treatment effect on apple fruit set, fruit set at harvest, and seed set at three

scales: the inflorescence (with a mean of 5.7 flowers), the branch (with a mean of 37.4 flowers), and

the whole tree (with an estimated mean of 741.4 flowers). Mesh was used to prevent insect

pollinators visiting flowers in the Excluded treatment. The Open treatment allowed insects free = supplementary pollination. 

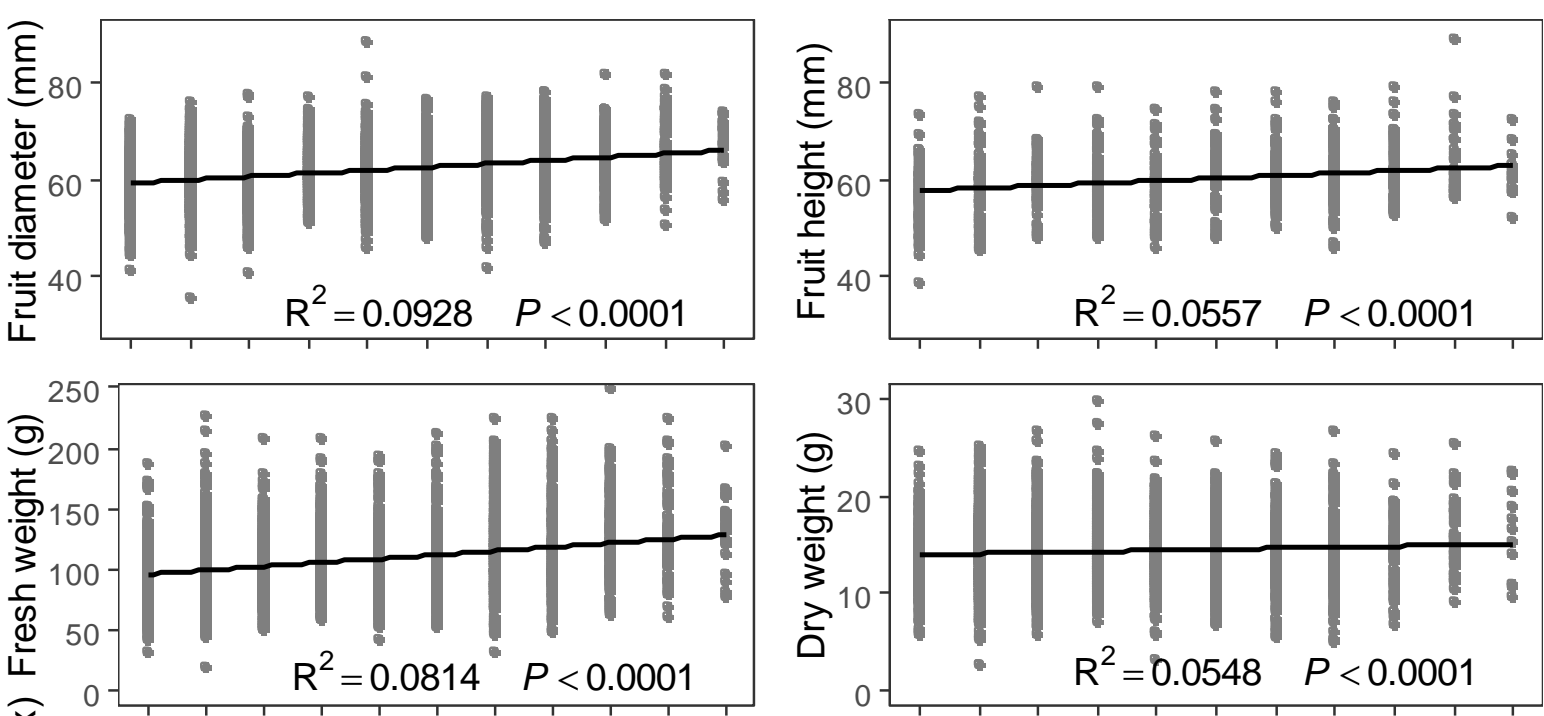

648
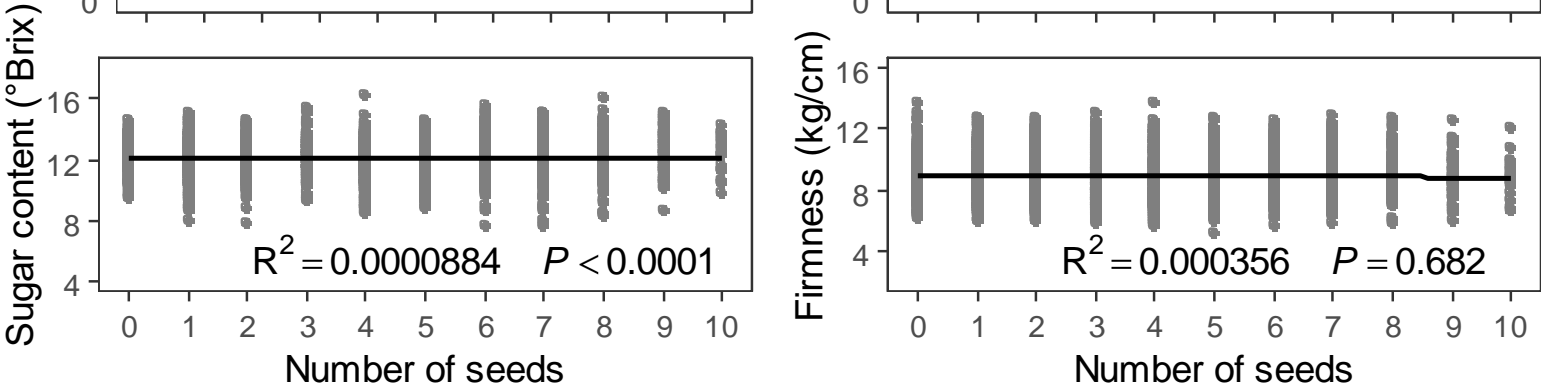

649 Figure 2. The relationship between seed number and measures of apple fruit quality. Regression

lines and $R^{2}$ values were calculated using simple linear models.

651

652

653

654 


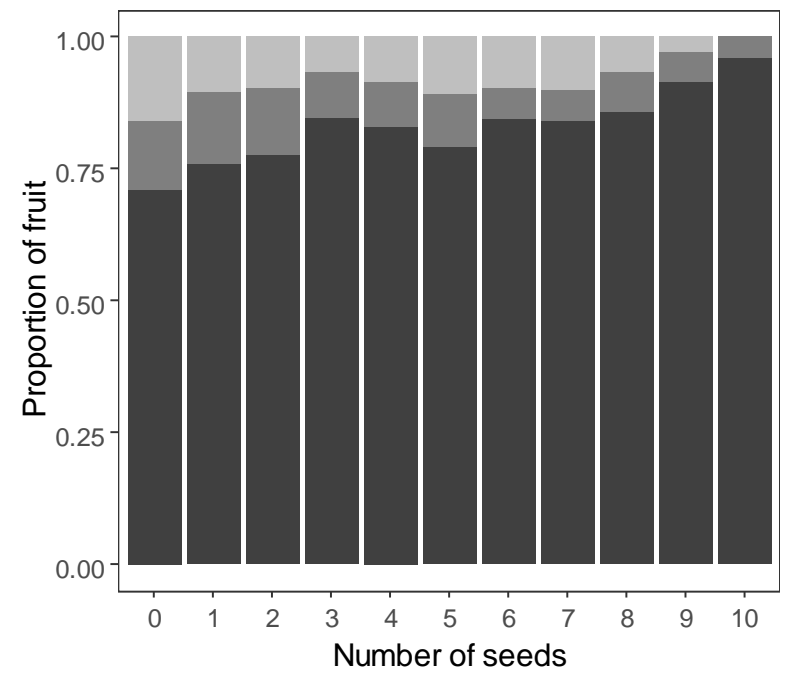

655

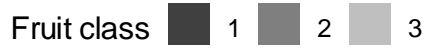

656 Figure 3. Apple fruit commercial class in relation to seed numbers (based on FAO standards). Class 1

657 is the highest class with Class 3 being unsuitable for sale as desert fruit. The number of seeds had a

658 significant positive effect on fruit class $(P<0.0001)$. These data are from 'Gala' apples which had

659 been commercially thinned prior to harvest. 